\title{
SATELLITE-BASED LOCATION DETERMINATION OF SMALL AIRCRAFT IN CASE OF ACCIDENTS AND DISASTERS
}

\author{
Altay Z. Aitmagambetov, \\ Institute of space technique and technology, Almaty, Kazakhstan, \\ altayzf@mail.ru \\ Denis I. Yeryomin, \\ Institute of space technique and technology, Almaty, Kazakhstan, \\ denis.e@bk.ru \\ Dinara G. Zhaxygulova, \\ Institute of space technique and technology, Almaty, Kazakhstan, \\ zhaxygulova.d@istt.kz. \\ Rimma A. Kaliyeva, \\ Institute of space technique and technology, Almaty, Kazakhstan, \\ keshrim95@gmail.com
}

DOI: $10.36724 / 2664-066 X-2020-6-2-33-37$

\begin{abstract}
From the moment the air/aero/aerial objects appeared the necessity of monitoring for them arose and were solved using different tools, such as radio communications, radio direction finding, radar and others. With the advent of global satellite navigation, the massive introduction of navigation equipment began in almost all areas of human activity and especially in mobile (moving) objects (cars, aircraft, ships, etc.). This allowed aircraft crews to accurately determine their coordinates in real time under any weather conditions. However, the organization of uninterrupted data transmission to ground control centers remained problematic. In this regard, aircraft monitoring systems were primarily installed on military and civil aircraft, while the other categories and types of aircraft were equipped only with communication systems. Thus, currently, there is the lack of navigation devices allowing flight monitoring and communication in small aviation. As a result, in case of emergency landing of small aircraft, it takes a lot of time and effort to
\end{abstract}

find its location, therefore providing emergency assistance to passengers and crew is not possible.

This problem can be solved by the system for determining the location of small aircraft using technologies of global navigation satellite systems and mobile satellite communications. This system includes devices for registering the location of the observed object, transmitting data via mobile cellular and satellite communications, processing, storage and displaying of data. The proposed system, by continuously recording and transmitting aircraft location data to the ground control center, helps minimize time and narrow the search area of the aircraft that made an emergency landing.

KEYWORDS: monitoring of flight trajectory, monitoring, small aircraft, global navigation satellite system, satellite communication, flight safety

Information about authors

Altay Z. Aitmagambetov, supervisor, AALR "Institute of space technique and technology", Almaty, Kazakhstan

Denis I. Yeryomin, Deputy Development Director, AALR "Institute of space technique and technology", Almaty, Kazakhstan Dinara G. Zhaxygulova, research fellow, AALR "Institute of space technique and technology", Almaty, Kazakhstan Rimma A. Kaliyeva, junior research fellow, AALR "Institute of space technique and technology", Almaty, Kazakhstan 


\section{INTRODUCTION}

Small aviation is backbone of general aviation (GA) and provides transportation of passengers and cargo, as well as agricultural, patrol, medical, training and other needs of the population and country. The category of small aircraft (AC) includes light and ultralight aircraft, as well as unmanned aerial vehicles weighing $10 \mathrm{~kg}$ or more. To date, the number of small aircraft is $89 \%$ of total number of aircraft. At the same time, small aircraft market continues to grow rapidly $[1,2]$ and requires the improvement of safety system, high-precision control of aircraft movement and elimination of errors based on misunderstandings between the pilot and dispatcher.

According to the Interstate Aviation Committee (IAC), in 2018, in civil aviation of states parties to interstate Agreement on Civil Aviation and the Use of Airspace, out of 58 aircraft accidents, 35 occurred with participation of small aircraft, as a result of which 44 people died. The main reasons for these incidents are human factor and equipment malfunction [3].

When flying small aircraft on a terrain that is so remote from radars that tracking their flight is impossible, in the event of an accident or catastrophe, the search for an aircraft emergency landing site is a difficult task, implementation of which requires significant time costs, which leads to a decrease in likelihood of saving people lives.

It is possible to significantly reduce the time and narrow search areas for aircraft that has made an emergency landing by providing continuous informing ground control points with navigation information about the flight, including data on the trajectory and flight parameters. In modern flight control systems, for navigation purposes, GPS / Glonass devices are used, which only let crew know the coordinates of aircraft without transmitting data to ground control points. Uninterrupted transmission of reliable navigation data from the global navigation satellite system (GNSS) in real time can be organized using latest advances in signal transmission through low-orbit mobile satellite communication systems [4,5].

In this regard, the creation of a monitoring system for flight trajectory of small aircraft using GNSS and loworbit satellite communication systems is an urgent task.

\section{Literature review}

Determining the location and parameters (speed, acceleration and direction of movement) of aircraft (AC) movement in space is one of the main tasks of navigation. Geotechnical, astronomical, radio-technical and lighting navigation aids can be used for the purpose of groundbased determination of location and parameters of aircraft movement [6]. The most common are radio navigation aids based on the emission and reception of radio waves by airborne and ground radio technical devices and measurement of radio signal parameters, carrying navigation information. The main system of radio navigation aids is radio navigation system (RNS). The RNS classification is shown in Figure 1 [7].

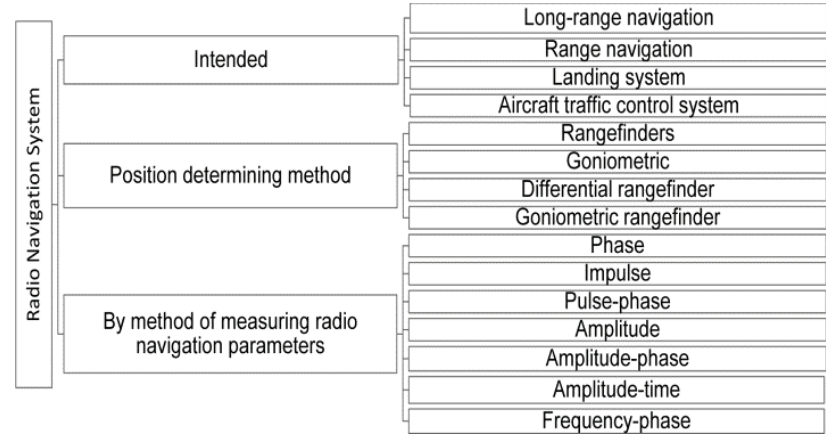

Figure 1. Classification radio navigation system

Currently, aircraft flight monitoring is carried out using the following systems [8]:

$-\mathrm{s}$ ort-range navigation and landing radio systems (VOR / DME - VHF Omni-directional Radio Range / Distance Measuring Equipment and ILS - instrument landing system);

- ong-distance navigation radio systems;

- satellite radio navigation systems (a system with the technology of automatic dependent surveillance-broadcast ADS-B - Automatic dependent surveillance-broadcast ADS-B).

Short-range navigation radio systems used are integrated radio navigation systems, including onboard equipment and ground-based omnidirectional azimuthrangefinder radio beacons and radio beacon groups. Principle of these systems operation is based on determining range and azimuth of observed object in relation to the ground radio beacon.

The system allows determining the coordinates of the aircraft not only on board, but also at the ground point. For ground determination of the range $\mathrm{R}$ and azimuth $\theta$ of the aircraft relative to the radio beacon (Figure 2), the ground beacon transmitter sends sounding pulses, which are relayed by the aircraft on-board equipment and then received by the ground equipment. Range $\mathrm{R} \mathrm{BC}$ from this radio beacon is calculated based on the measured time delay of the response signal compared to interrogation signal. Azimuth $\theta$ is determined from angular position of radiation pattern at time of response signal arrival [9].

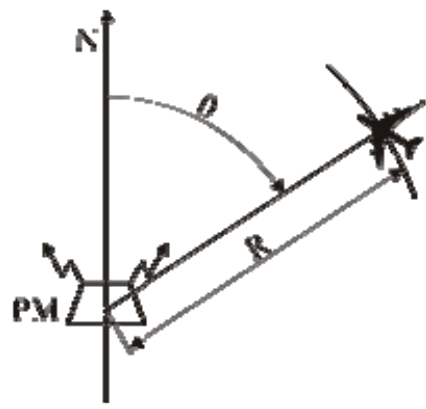

Figure 2. Scheme for determining the position of aircraft by the goniometric-rangefinder method

Short-range radio systems allow solving the following tasks:

- continuous determination of aircraft position both on board and on the ground; 
- performing a flight along a given route;

- taking the aircraft to any given point, regardless of visibility conditions, indicating the moment of approach to the point and moment of its passage;

- $\mathrm{i}$ plementation of controlled cloud penetration and landing approach;

- observation from the ground by all-round visibility indicator (IKO) for aircraft, determination of their coordinates and aircraft identification, if they are equipped with aircraft identification system equipment.

Radio engineering system in short-range navigation operates on ultrashort waves, so the exchange of signals between aircraft and ground beacon is possible only at line-of-sight ranges, which mainly depends on flight altitude, for example, at a flight altitude of $10 \mathrm{~km}$, the range is up to $380 \mathrm{~km}$. In mountainous areas and in the presence of obstacles in path of ultrashort waves propagation, the range of system decreases.

The most common radionavigation approach system is the glide path system. This system consists of localizer and glide path radio beacons, forming a landing and radio beacon group and emitting radio signals into space. Localization and glide path beacons are installed in close proximity to the runway (runway). Reception and processing of beacon signals by onboard equipment provides guidance of the aircraft in horizontal plane (along the course) and in the vertical plane (along the glide path). A schematic representation of aircraft landing process using the course-glide path system is shown in Figure 3 [10].

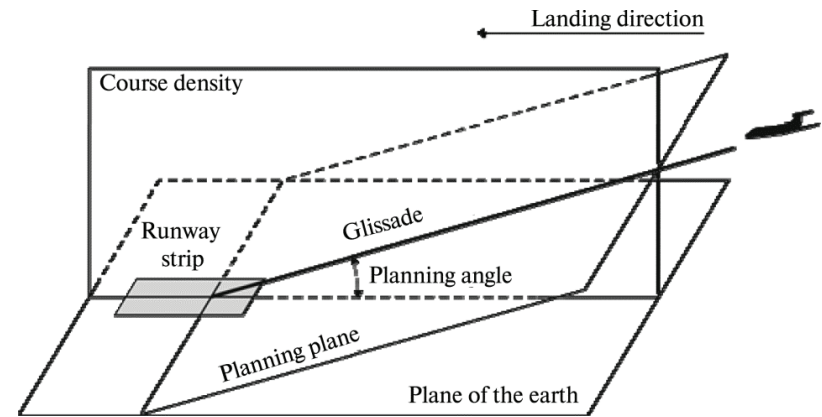

Figure 3. Scheme of aircraft landing on the course-glide path system

Pulse-phase and phase long-range navigation radio systems are widespread, since they allow objects to determine their coordinates when they are not in the line of sight of radio beacons. These systems use ultra-long waves, for which there is a weak dependence of the attenuation of the field strength on the distance, which makes it possible to ensure the range of the system more than $900 \mathrm{~km}[8]$.

The basis of long-distance navigation radio systems are reference stations with known coordinates, which only send navigation signals. In turn, the on-board equipment of aircraft receives and processes signals.

To determine the coordinates of the aircraft, the difference-ranging method is used, based on the construction of lines of equal difference distances. The principle of the differential-rangefinder method is to measure time difference between the arrival of signals from pair of stations using a receiver indicator. This difference defines the line of position of aircraft in hyperbola form. To determine the exact coordinates of the aircraft, at least two pairs of stations are required [9].

Long-range radio-technical systems solve the following tasks:

- de ermination of aircraft location using special maps with a hyperbolic grid;

- determination of flight navigation elements;

- re aying signals for transmitting the coordinates of aircraft in distress and when searching for crews that have made an emergency landing.

The most advanced are satellite radio navigation systems. System with ADS-B technology allows monitoring the aircraft movement and receiving aircraft movement parameters both on board the aircraft and at ground points. This system is characterized by highest accuracy of aircraft navigation parameters determination among all known systems. ADS-B is based on GPS global positioning system or inertial navigation system for determining the exact coordinates of an aircraft in space [11].

Aircraft equipped with ADS-B technology are capable of transmitting information: course, altitude, horizontal and vertical speed, to other aircraft, as well as to ground points located at a distance of up to $440 \mathrm{~km}$.

When using a system with ADS-B technology, an accurate map of aircraft location is displayed on radar station screens for aircraft movement and on the aircraft board.

System with ADS-B technology (ADS-B) consists of the following components (Figure 4):

- transmitting subsystem, which performs the functions of generating and transmitting reports on the sending aircraft / vehicle / obstacle;

- data line broadcasting mode;

- receiv ng subsystem, which includes the functions of receiving and assembling reports on the receiving aircraft / vehicle or in the receiving ground system.

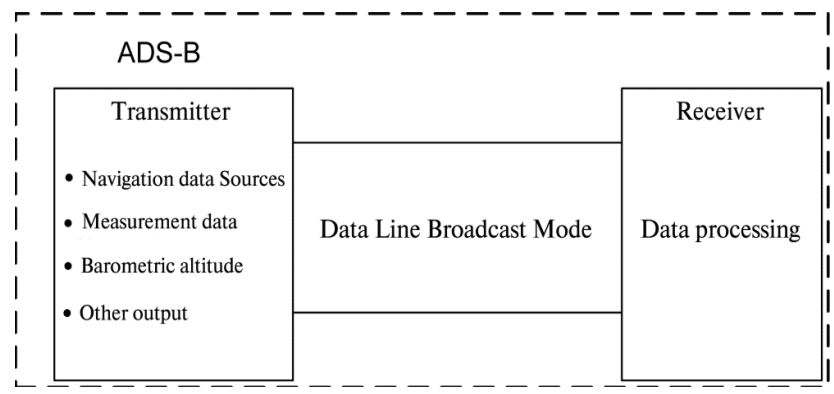

Figure 4. System components with ADS-B technology

During the system operation with ADS-B technology, aircraft determines its position using the GNSS system, then transmitter installed on aircraft transmits data via a radio signal. The radio signal is received by receivers installed on other aircraft and ground points, where the received information is processed. The main advantages of radio navigation aids are their ability to operate in almost any meteorological conditions day and night, to make measurements with high accuracy and determine absolute coordinates of aircraft and ground speed.

However, radio equipment is subject to natural and organized interference, limited in range, and accuracy of their measurements decreases as aircraft moves away from the ground subsystem and radar landmark. In this 
regard, use of radio-technical navigation means is impossible to ensure continuous monitoring during flight and location determination in case of accidents and disasters of small aircraft.

\section{Flight trajectory monitoring system for small aircraft}

The developed system for flight trajectory monitoring of small aircraft is an automated system that collects telemetry and navigation data, data transmission using mobile cellular or satellite communication systems, receiving, processing, archiving data and issuing information to system users.

The system contains three main components terminal, data processing center (DPC) and dispatch center (DC). Main components of the terminal are: navigation module, communication modules, barometric sensor and terminal status sensors. The terminal is installed on board aircraft and provides registration of input information (telemetry and navigation data) about state of monitored aircraft and data transmission via mobile cellular or satellite communications to data processing center. Data center provides automatic, continuous and parallel in time data reception from all registered terminals, data processing and archiving, and provision of processed data to the DC. Control center displays position data and other aircraft parameters, which simplify aircraft identification and search operations in the emergency event.

\section{Algorithm of the system for small aircraft flight trajectory monitoring}

The algorithm for small aircraft flight trajectory monitoring is presented in form of a UML (Unified Modeling Language) activity diagram (Figure 5).

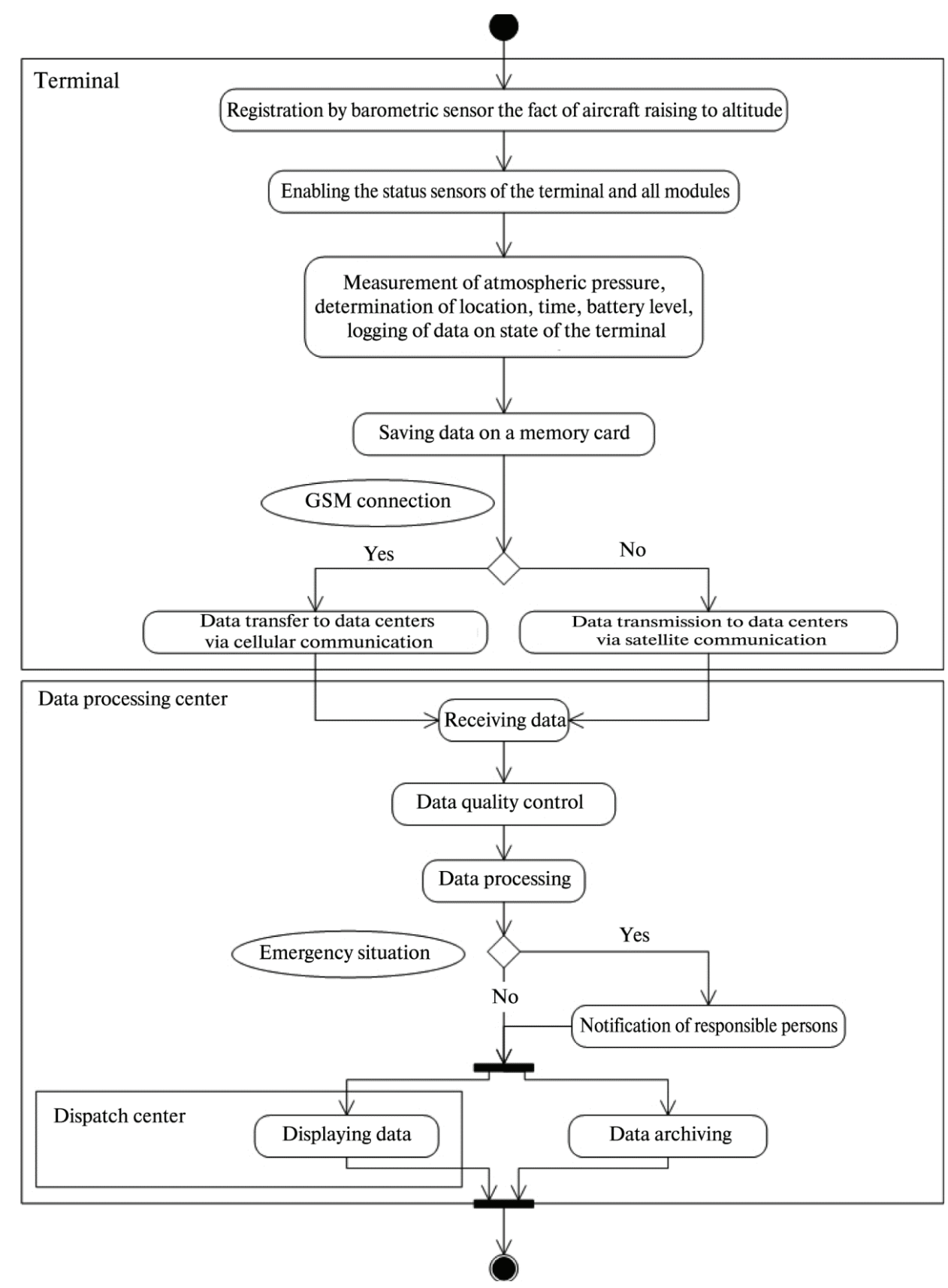

Figure 5. Monitoring system activity diagram of small aircraft flight trajectory 
The terminal status sensors (terminal integrity sensor and cable control sensor) and the terminal barometric sensor are always on. When aircraft is raised to an altitude, barometric sensor registers the change in atmospheric pressure and terminal modules are switched on.

Further, the main telemetry and navigation data are formed: measurement of atmospheric pressure, determination of aircraft location, time and date, battery charge level, data registration from sensors for monitoring the integrity of the terminal. The received data is saved on the terminal memory card.

During a communication session, which occurs with a predetermined period, accumulated data packet is transmitted to data processing center mainly via GSM mobile cellular communication, and in its absence - via Iridium mobile satellite communication. The controller of aircraft flight trajectory monitoring system can change data transmission frequency during the communication session with terminal.

Data processing center receives data from the terminal, performs data integrity control using a cyclic redundancy check (CRC) in order to identify erroneous data and process them. When processing the data, authorization of flight is established and analysis for the presence of an emergency situation. In cases of observation of an unauthorized flight or detection of an abnormal situation, for example, an aircraft crash (a sharp increase in pressure registered by a barometric sensor), violation of terminal integrity, absence of a signal from the terminal, and others, system provides for notification of the situation of responsible persons, as well as a system message to the dispatcher on duty.

All collected information, including about sent alarm notifications, is archived in the data center and simultaneously displayed in the dispatch center in the form of a terminal location map, graphs of monitoring sensor readings and aircraft information (registration number, model, owner, operator, flight hours, latest technical service).

\section{CONCLUSION}

Implementation of proposed system for monitoring flight trajectory of small aircraft will allow continuous small aircraft trajectory monitoring and flight parameters, remotely identify registered air objects and collect statistical information about their flights. As a result, the level of flight safety of small aircraft will increase.

The use of system is also of great social importance, since in the event of an accident or catastrophe, system will minimize the time it takes to detect an aircraft emergency landing (catastrophe) site and reduce the aircraft search area, which will increase the likelihood of saving people.

Thanks to the system application, it will be possible to carry out technical control over the fleet of small aircraft, to reveal facts of unauthorized aircraft flights, to control the activities of public and private owners of small aircraft.

\section{REFERENCES}

1. A.V. Badulina (2014). Current state and development prospects of the global small aircraft market, Russian Foreign Economic Journal, 5, pp. 68-79.

2. L.B. Sobolev (2016). A high mission of general aviation, Economic Analysis: Theory and Practice, 15(3), pp. 4-16.

3. Safety status reports [online]. Available at: https://mak-iac.org/rassledovaniya/bezopasnost-poletov/ (Accessed: 14 August 2019).

4. A.V. Katsura, A.R. Akzigitov, A.S. Andronov, (2016). Razrabotka bortovogo ustroystva sputnikovogo monitoring vozdushnyh sudov, Vestnik SibGAU, 17 (1), pp. 125-130.

5. I.G. Kirpichev, D.V. Petrov, (2012). Advanced development of software for monitoring of processes of aircraft maintenance in application to solving tasks of the government supervision over civil aircraft airworthiness, Civil Aviation High TECHNOLOGIES, 175, pp. 13-17.

6. Yu.N. Saraisky, I.I. Aleshkov, 2010) Aeronavigatsiya. Saint-Petesburg: SPBGUGA.

7. R.A. Gamiashev, I.N. Kratsan, (2011). Radionavigatsionnyye sistemy i ih klassifikatsiya, Aktualnye problem aviatsii I kosmonavtiki, 1(7), pp. 293-295.

8. V.I. Baburov, et al. (2012). Local global radio systems of navigation and information, Civil Aviation High TECHNOLOGIES, 180, pp. 123-128.

9. A.V. Bazhenov, et al. (2007). Radionavigatsionnyye sistemy. Stavropol: SVVAIU(VI).

10. O.N. Skrypnik, Radionavigatsionnyye sistemy vozdushnykh sudov. Moscow: INFRA-M.

11. Sistema Avtomaticheskogo Zavisimogo Nablyudeniya $\mathrm{v}$ Rezhime Radioveshchaniya (ADS-B) dlya vedeniya nablyudeniya VOZDUKH - ZEMLYA [online]. Available at: http://adsbradar.ru/AN-Conf 11-WP/127/ (Accessed: 16 August 2019). 